NBER WORKING PAPER SERIES

\title{
MINIMUM ASSET REQUIREMENTS AND \\ COMPULSORY LIABILITY INSURANCE AS SOLUTIONS TO THE JUDGMENT-PROOF PROBLEM
}

\author{
Steven Shavell \\ Working Paper 10341 \\ http://www.nber.org/papers/w10341 \\ NATIONAL BUREAU OF ECONOMIC RESEARCH \\ 1050 Massachusetts Avenue \\ Cambridge, MA 02138 \\ March 2004
}

Samuel R. Rosenthal Professor of Law and Economics, Harvard Law School, and Research Associate, National Bureau of Economic Research. I thank Louis Kaplow for comments, Sergey Lagodinsky, Frederick Pollock III, and Ziv Preis for research assistance, and the John M. Olin Center for Law, Economics, and Business at Harvard Law School for research support. The views expressed herein are those of the authors and not necessarily those of the National Bureau of Economic Research.

(C2004 by Steven Shavell. All rights reserved. Short sections of text, not to exceed two paragraphs, may be quoted without explicit permission provided that full credit, including $\mathbb{C}$ notice, is given to the source. 
Minimum Asset Requirements and Compulsory Liability Insurance As Solutions to the Judgment-Proof Problem

Steven Shavell

NBER Working Paper No. 10341

March 2004

JEL No. D00, K13, K20, L5

\begin{abstract}
$\underline{\text { ABSTRACT }}$
Minimum asset and liability insurance requirements must often be met in order for parties to participate in potentially harmful activities. Such financial responsibility requirements may improve parties' decisions whether to engage in harmful activities and, if so, their efforts to reduce risk. However, the requirements may undesirably prevent some parties with low assets from engaging in activities. Liability insurance requirements tend to improve parties' incentives to reduce risk when insurers can observe levels of care, but dilute incentives to reduce risk when insurers cannot observe levels of care. In the latter case, compulsory liability insurance may be inferior to minimum asset requirements.
\end{abstract}

Steven Shavell

Harvard Law School

1575 Massachusetts Avenue

Hauser Hall 508

Cambridge, MA 02138

and NBER

shavell@law.harvard.edu 


\title{
Minimum Asset Requirements and Compulsory Liability Insurance As Solutions to the Judgment-Proof Problem
}

\author{
Steven Shavell \\ (C) 2004. Steven Shavell. All rights reserved.
}

\section{Introduction}

Requirements that parties have assets or liability insurance coverage of at least a prescribed magnitude in order to participate in an activity are frequently imposed. Individuals must sometimes satisfy such financial responsibility requirements, a notable example concerning driving, and business entities often face these requirements, for instance concerning transportation of hazardous wastes, construction, and banking operations. ${ }^{1}$

In this article, a principal rationale for minimum asset and liability insurance requirements is considered: Potential injurers may make superior decisions whether to engage in an activity and, if they do so, may have stronger incentives to reduce risk, when they have at stake at least the required level of assets and/or liability insurance coverage if they are sued for causing harm. ${ }^{2}$

In section 2 of the article, asset requirements are investigated in the absence of liability insurance. A standard model is studied in which individuals make two choices: whether to engage in a potentially harmful activity; and if so, how much care to exercise to reduce the risk of harm. ${ }^{3}$ Individuals are assumed to be held liable for harm caused. If they have assets at least

\footnotetext{
${ }^{1}$ On driving, see Jerry 1996, pp. 859-63; on hazardous wastes, see for example FLA. STAT. Ch. 403.724 (2002); on construction, see for example WIS. ADMIN. CODE $\$ 5.31$ (2002); and on banking, see Jackson and Symons 1999, pp. 184-207.

${ }^{2}$ Another rationale for asset and liability insurance requirements is to increase victims' ability to obtain compensation through suit for their losses; this rationale is mentioned in the concluding section.

${ }^{3}$ The parties in the model are individuals, as opposed to firms, but many (not all) of the conclusions should carry
} 
equal to the harm that they might create, both of their incentives will be optimal. They will engage in the activity if and only if their benefits would exceed the expected harm caused; and if they engage in the activity, they will choose the optimal level of care. If individuals' assets are less than the potential harm, however, they will engage too often in the harmful activity, as they will not then face (effective) expected liability equal to the expected harm, and they will similarly lack incentives to take optimal care.

A minimum asset requirement alleviates the problem that individuals might engage in the activity too often. However, an asset requirement has a disadvantageous effect: Some of the individuals with assets below the required level ought to engage in the activity, because the benefits they would obtain exceed the expected harm they would cause, even though this expected harm is higher than is optimal due to their dulled incentives to take care. The optimal asset requirement reflects the tradeoff between this disadvantageous effect and its advantages.

In section 3 of the article, compulsory liability insurance is added to the analysis. The usual rule of compulsory liability insurance is studied: in order to engage in an activity, parties must purchase liability insurance coverage in a stipulated amount or else have assets sufficient to make up any shortfall between their coverage and that amount. ${ }^{4}$ The optimal liability insurance requirement is considered, and liability insurance requirements are compared to pure asset requirements.

Liability insurance requirements affect individuals' decisions about engaging in the potentially harmful activity. A party with assets less than the possible harm can pay at most his

over to a model with firms, as discussed in the concluding section.

${ }^{4}$ Most of the statutes that I have examined follow essentially this rule; see, for example, FLA. STAT. Ch. 403.724 
assets and thus faces a commensurately low expected liability. But if the party must purchase liability insurance in order to engage in the activity, he will bear a higher expected liability. A person with assets of $\$ 100,000$ who might cause harm of $\$ 1,000,000$ with a probability of $1 \%$ faces an expected liability of only $\$ 1,000$ if he has no liability insurance, whereas if he is led to purchase coverage of, say, $\$ 500,000$, he will have to pay (and can afford to pay) a premium of $\$ 5,000$. That liability insurance requirements result in individuals with low assets paying for a higher fraction of the expected harm, in the form of insurance premiums, than they otherwise would bear may improve their decisions whether to participate in the activity. However, some individuals may not have sufficient assets to pay the premium for the required coverage even though they would obtain benefits exceeding the expected harm. ${ }^{5}$ For this reason (and another to be noted below, when insurers cannot observe care) the optimal required level of liability insurance coverage may well be less than full.

Liability insurance requirements also influence the level of care exercised by individuals. If insurers can observe care levels, then when individuals buy coverage, their premiums reflect the care they exercise, and therefore they have a reason to take care in addition to that due to the liability they might otherwise bear. The motive to reduce risk by .1\% of a person who has assets of $\$ 100,000$ and no liability insurance is $\$ 100$, whereas if he has a liability coverage of $\$ 500,000$, his premium-related incentive to reduce risk by .1\% is $\$ 500$. This suggests two of the

(2002).

${ }^{5}$ In the example of this paragraph, if a person's benefit from the activity would exceed the $\$ 10,000$ expected harm, but his assets were less than $\$ 10,000$, it would be desirable for him to engage in the activity, yet he would not be able to do so under a liability insurance requirement of coverage equal to the full harm of $\$ 1,000,000$. There are two reasons that a party might have benefits exceeding the expected harm but lower assets: the benefits might be nonmonetary (such as the benefits from driving a car often are); the benefits might be monetary but only be received after engaging in the activity, so would be unavailable to use to purchase insurance beforehand. See also notes 15 and 24 and section 4(a). 
results to be shown: that when insurers can observe care, liability insurance requirements tend to be socially desirable; and social welfare under the optimal liability insurance requirement is superior to that under the optimal pure asset requirement, which, note, does not affect the incentives to take care of individuals who do engage in the activity.

If insurers cannot observe care levels, so that insurance premiums cannot be linked to care levels, then the purchase of liability insurance coverage generally dulls, rather than increases, incentives to take care, for two possible reasons: the usual moral hazard -- that coverage lowers an individual's exposure to liability; and a premium-related moral hazard -- that the payment of the premium itself reduces the magnitude of assets that a person has at stake (a person with assets of $\$ 100,000$ who pays $\$ 10,000$ as a premium for insurance coverage will have at most $\$ 90,000$ at stake rather than $\$ 100,000$ ). The dilution of incentives due to insurance coverage implies that when insurers cannot observe care, required liability insurance coverage may be socially undesirable and inferior to a pure asset requirement, for the latter does not dilute incentives of individuals who engage in the activity.

In section 4 of the article, concluding comments are made on several issues: firms as injurers; the endogeneity of assets (for example, assets can be shielded from liability); alternatives to asset and liability insurance requirements (such as vicarious liability, barring purchase of liability insurance, and direct safety regulation); and the goal of victim compensation.

Regarding previous literature, the point of departure for this article is study of the judgment-proof problem -- the incentive problem that arises when parties' assets are not sufficient to pay liability judgments equal to the entire harm that might be caused; see Summers 
(1983) and Shavell (1986).

Asset requirements as a general remedy for the judgment-proof problem do not appear to have been investigated before; thus the tradeoff between the advantages of asset requirements and the drawback of preventing parties who ought to engage in an activity from doing so apparently has not previously been examined. However, Pitchford (1995) briefly considers asset requirements as a means of inducing investors to increase equity in firms. ${ }^{6}$ Also, bank solvency regulation (typically in the form of capital-to-asset ratios) has been studied as a device for lowering the risk of bank failure; see generally Freixas and Rochet (1997). ${ }^{7}$ In that literature it is often assumed that banks carry government insurance protecting depositors and that the insurance is not risk-priced; this creates an incentive for banks to make risky loans, and thus a possible need for solvency regulation. ${ }^{8}$

Compulsory liability insurance as a method of alleviating the judgment-proof problem has been addressed in a number of articles, including Shavell (1986, 2000), Jost (1996), and Polborn (1998). This literature points out that liability insurance requirements can improve the decision whether to engage in an activity and that, if insurers can observe care, also increases

\footnotetext{
${ }^{6}$ In his model, asset requirements cause owners of potentially judgment proof firms to invest more capital in them (see his Proposition 4), which then leads firms to exercise more care (see section 4(b) below for further remarks on this subject). By contrast, in the model here, as has been emphasized, asset requirements prevent parties with low assets from engaging in harmful activities.

${ }^{7}$ Section 9.5 of their book reviews the literature on bank solvency regulations, including Kahane (1977), Kim and Santoremo (1988), and Rochet (1992).

${ }^{8}$ Another reason for solvency regulation in the banking context is that depositors are usually presumed not to know bankruptcy risk; this implies that even if depositors were not insured by the government, the rates that a bank would have to pay to depositors would not increase if the bank's risk of bankruptcy increased. A further reason for solvency regulation is that one bank's failure might to lead to other bank failures, a type of negative externality. Again see the review of the literature in section 9.5 in Freixas and Rochet (1997) for details.
} 
levels of care; but it does not consider that liability insurance requirements can worsen the decision to engage in an activity, it does not fully analyze the moral hazard created by insurance when insurers cannot observe care, and it does not compare liability insurance requirements to pure asset requirements.

Finally, there is literature on other policies that are employed to combat the judgmentproof problem, the most closely-related being articles on the imposition of vicarious liability on parties who have a contractual relationship with the injurer; see, for example, Sykes (1984), Shavell (1987), Pitchford (1995), Boyer and Laffont (1997), Boyd and Ingberman (1997), and Hiriart and Martimort (2003). In particular, Pitchford (1995) emphasizes an effect of lender liability that is equivalent to the premium-related moral hazard mentioned above; this literature on alternative policies will be mentioned in the concluding section.

\section{Asset Requirements}

Assume that injurers are risk-neutral individuals who may choose to engage in an activity from which they would obtain a gain but that might also result in harm, with a probability depending on their level of care. Define the following notation.

$g=$ gain to an individual from engaging in the activity; $g \geq 0$;

$f(g)=$ probability density of $g$ across individuals; $f(g)>0 ;{ }^{9}$

$x=$ level of care exercised by an individual; $x \geq 0$;

$p(x)=$ probability of harm; $0<p(x)<1 ; p^{\prime}(x)<0$ and $p^{\prime}(x) \rightarrow-\infty$ as $\mathrm{x} \rightarrow 0 ; p^{\prime \prime}(x)>0$;

$h=$ level of harm; $h>0$.

${ }^{9} \mathrm{~A}$ particular individual's gain is certain; different individuals obtain different gains. 
Social welfare $S$ is the gains that individuals obtain from engaging in the activity minus the cost of care ${ }^{10}$ exercised by them and expected harm caused; that is, social welfare is the integral of $g$ $-(x+p(x) h)$ over all individuals who engage in the activity. The state is assumed to know the density $f$, the function $p$, and the harm $h$, but not to observe the gain $g$ or care $x$.

Socially optimal behavior is easily described: If an individual engages in the activity, he should choose $x$ to minimize social costs -- the disutility cost of care plus expected harm -- or

$$
x+p(x) h,
$$

so that $x$ should satisfy the first-order condition

(2) $\quad 1=-p^{\prime}(x) h$;

that is, the marginal cost of care should equal the marginal expected reduction in harm. Denote the optimal $x$ by $x *$ and observe that it is positive for any positive $h .{ }^{11}$ A person should engage in the activity if and only if ${ }^{12}$

$$
g \geq x^{*}+p\left(x^{*}\right) h
$$

Suppose that individuals are held strictly liable ${ }^{13}$ for causing harm: A person who causes harm $h$ is supposed to pay $h$ to the victim. However, an individual may not have assets sufficient to pay for the harm he caused. Specifically, assume that individuals differ in their holdings of assets; let

$$
\begin{aligned}
y & =\text { level of assets of an individual } \\
w(y) & =\text { probability density of assets across individuals, where } y \geq 0, w(y)>0,
\end{aligned}
$$

\footnotetext{
10"Cost" of care will be used interchangeably with "level" of care.

${ }^{11}$ This is guaranteed by the assumption that $p^{\prime}(x) \rightarrow-\infty$ as $\mathrm{x} \rightarrow 0$.

${ }^{12}$ If (3) holds with equality, social welfare is of course unaffected by whether the person engages in the activity, but for concreteness let us make the assumption that he ought to engage in it in this case. (Similar assumptions will be made below without further comment.)
} 
and where, for simplicity, it is assumed that the distributions of assets $y$ and of gains $g$ are independent. The state is assumed to be able to observe $y$ and to know the density $w$. If a person causes harm $h$, he can pay only $y$ if his assets are lower than $h$. Hence, a person's cost of care plus expected liability payments if he engages in the activity equal

$$
x+p(x) \min (y, h)
$$

and let the person's choice of $x$ that minimizes (4) be written $x(y)$. Note that the fact that a person can pay a liability judgment fully equal to his assets $y$ reflects the assumption that his cost of care is a utility cost; for if care involves a monetary expenditure, the assets that a person would have available to pay in a judgment would be only $y-x .^{14}$ Similarly, the fact that a person can pay a judgment of only $y$ reflects the implicit simplifying assumption that $g$ cannot also be paid (otherwise the available assets would be $y+g$ ). This assumption holds when $g$ is a utility benefit. $^{15}$

We have, ${ }^{16}$

PROPOSITION 1. If an individual's assets $y$ are less than the harm $h$ that he might cause, he may engage in the harmful activity when that is socially undesirable (that is, when $g<x(y)+$ $p(x(y)) h)$ and, if so, will exercise inadequate care (that is, $\left.x(y)<x^{*}\right)$. Also, the lower is $y$, the

\footnotetext{
${ }^{13}$ If liability were instead based on the negligence rule, the character of the conclusions would not be altered.

${ }^{14}$ If $x$ is monetary, complications that are distracting for the purposes of this article would be introduced into the analysis. Namely, because expenditures on care would be expenditures of money that might otherwise be paid as liability judgments, care effectively becomes cheaper (even raising the theoretical possibility that a person with low assets would exercise excessive care); this effect is less important the lower the probability of harm. On these issues, see Beard 1990.

${ }^{15}$ An individual's gain from an activity is frequently nonmonetary; as noted, an example concerns driving (say, to see a movie). Of course, in many contexts, and generally for firms, gains are monetary. If gains are monetary and would be available to be paid in the event of an accident, the thrust of the conclusions would not change as long as $y$ $+g<h$, but the level of care would generally be higher since it would be chosen to minimize $x+p(x)(y+g)$ rather than $x+p(x) y$.
} 
lower is $x(y)$ and the higher are social costs (that is, $x(y)+p(x(y)) h)$.

Notes. This proposition (and others below) is proved in the appendix to the paper. The reason for it is clear: If a person's assets are less than harm, the (effective) expected liability is less than expected harm, so a person will not bear the full social cost of his activity; hence he may decide to engage in it when his gain $g$ is less than $x(y)+p(x(y)) h$. Relatedly, because his expected liability is less than expected harm, the marginal benefit to him of taking more care is less than the social marginal benefit, implying that $x(y)$ is less than $x^{*}$, and this effect is accentuated the lower are his assets.

Now suppose that the state can regulate entry into the activity by use of an asset requirement: Individuals cannot engage in the activity unless their assets are at least $y .{ }^{17}$ Social welfare $S$ as a function of the asset requirement $y$ is

$$
\left.S(\underline{y})=\int_{\underline{y}}^{\infty}\left\{\int[g-(x(y)+p(x(y)) \min (x, h)) h)\right] f(g) d g\right\} w(y) d y
$$

because, for every permitted $y$, an individual will engage in the activity if his gain is at least equal to (4). Denote the optimal $y$ by $y^{*}$. We then have the following.

PROPOSITION 2. It may be desirable to impose a positive asset requirement. A necessary and sufficient condition for this to be true, for $y^{*}>0$, is that the mean gain that individuals would obtain from the activity is less than the expected harm when no care is exercised, that is, $\mathrm{E}(g)<$ $p(0) h$. Also, the optimal requirement $y^{*}$ is less than the harm $h$.

Notes. Imposing an asset requirement $\underline{y}$ has the advantage that it prevents individuals

\footnotetext{
${ }^{16}$ This result is developed in Shavell 1986.

${ }^{17}$ Direct regulation of safety is not possible because the state cannot observe $x$.
} 
with the least wealth from engaging in the activity, and there is a double reason why it may be desirable to do so: These individuals would exercise the least care, meaning that they would create the most risk, if they engaged in the activity; and they would have the weakest liabilityrelated incentives to take the expected harm they create into account in deciding whether to engage in the activity because their assets are lowest. In particular, the social welfare benefit from use of $y$ derives from preventing individuals from engaging in the activity who would otherwise have done so but should not have, that is, those for whom $x(y)+p(x(y)) y<g<x(y)+$ $p(x(y)) h$. There is also a social welfare disadvantage from use of $y$, due to its preventing individuals from engaging in the activity who would otherwise have done so and should have, that is, those for whom $x(y)+p(x(y)) h<g$.

If $\mathrm{E}(g)<p(0) h$, then the group with no assets are on average desirable to prevent from engaging in the activity, which suggests why this condition implies that a positive asset requirement is advantageous. Also, observe that the social welfare benefit from use of $y$ exists only for $y<h$, explaining why $y^{*}$ cannot exceed $h$. To understand why $y^{*}$ must be strictly less than $h$, note that if $y$ is lowered marginally from $h$, those individuals who are led to engage in the activity who should not do so cause no first-order loss in social welfare (since their assets are essentially equal to $h$, their expected liability is essentially equal to expected harm, so their incentives are essentially optimal), but the individuals who are now permitted to engage in the activity who ought to do so generate a positive first-order gain in social welfare.

\section{Liability Insurance and Asset Requirements}


Let us now examine a financial responsibility rule under which, in order to engage in the harmful activity, parties must purchase enough liability insurance so that their coverage plus available assets meet the required amount. Let

$$
\begin{aligned}
& \underline{z}=\text { financial responsibility requirement } ; \underline{z} \geq 0 ; \\
& c=\text { insurance coverage in the event of harm; } c \geq 0 ; \text { and } \\
& \pi=\text { insurance premium. }
\end{aligned}
$$

Thus, the rule under study is that, in order to engage in the activity, $y-\pi+c$ must be at least $\underline{z}$. As mentioned in the Introduction, this rule is typical, and we will call it a liability insurance and asset requirement. $^{18}$

We will now describe behavior under liability insurance and asset requirements. We will also compare social welfare under the optimal $\underline{z}$, denoted $\underline{z}^{*}$, to that under the optimal pure asset requirement $y^{*}$. We will also consider social welfare under $\underline{z}=h-$ a requirement that a person have assets plus liability coverage equal to the full harm - because this is a natural and intuitively appealing rule (even though, as will be seen, it is not generally optimal; $\underline{z}^{*}$ may well be less than $h$ ).

We will assume that liability insurance is sold by a competitive insurance industry facing no administrative costs, so that premiums are actuarially fair, and we will consider two cases: where insurers can observe the level of care $x$ and link insurance policy terms to it; ${ }^{19}$ and where

\footnotetext{
${ }^{18}$ Under a pure liability insurance requirement, which the parties cannot use any assets to satisfy, the conclusions reached would be similar, but the optimal level of the requirement would generally differ (a pure liability requirement of a particular level of coverage is a rough equivalent of a higher requirement which can be satisfied with coverage or assets).

${ }^{19}$ It is assumed that, even when insurers can observe care $x$ and contract on it, the state (which might have less expertise than insurers in monitoring $x$ ) does not observe $x$ and directly regulate it.
} 
insurers cannot observe the level of care. Also, we will continue to assume that individuals are risk neutral.

3.1 Insurers are able to observe the level of care. In this case, since insurers can observe care $x$ and thus know $p(x)$, the premium $\pi$ that they will charge is $p(x) c$. Let us state several claims about insurance purchases given any $\underline{z} \leq h$ before proceeding with the analysis. ${ }^{20}$

(a) If $y \geq \underline{z}$, so that individuals do not need to purchase insurance coverage to engage in the activity, individuals will not buy insurance coverage. A person with such a $y$ will be worse off if $y<h$ and he buys coverage, for without coverage his liability payment will be $y$, whereas if he buys coverage, he will be effectively paying for positive liability above $y$, that is, for liability that he would not otherwise have to bear. ${ }^{21}$ If $y \geq h$ and he buys coverage, he will not effectively be increasing his liability, as he already has the assets to pay $h$; thus, he will be indifferent between buying coverage and not, and we can assume he will not buy coverage.

(b) If $y<\underline{z}$, so that individuals must purchase coverage in order to engage in the activity, individuals will buy the minimum necessary coverage - such that $y-\pi+c=\underline{z}$. The explanation is that, were an individual to purchase enough coverage so that he could pay more than $\underline{z}$, he would be implicitly paying for liability that he does not need to bear, so would be made worse off.

\footnotetext{
${ }^{20}$ The reasons for the points are sketched; they are proved in the appendix (where the case of $\underline{z}>h$ is also addressed).

${ }^{21}$ Consider for example a person with assets of $\$ 10,000$ and assume that harm is $\$ 50,000$ and that the probability of harm is $10 \%$ (in fact the probability is endogenous, but this can be ignored for present purposes). Suppose the person purchases coverage of $\$ 1,000$. Then his premium would be $\$ 100$, and his remaining wealth would be $\$ 9,900$. Consequently, his expected liability-related expenses would be $\$ 100+.10(\$ 9,900)=\$ 1,090$, whereas if he does not buy coverage, his expected liability-related expenses are lower, .10 $(\$ 10,000)=\$ 1,000$.
} 
(c) If $y<\underline{z}$, individuals who engage in the activity choose care of $x(\underline{z})$ and bear expected costs of $x(\underline{z})+p(x(\underline{z})) \underline{z}$. From (b), we know that an individual's available assets $y-\pi$ plus coverage $c$ equal $\underline{z}$. Because the probability of losing one's available assets and the premium $\pi=$ $p(x) c$ depend on $x$, an individual will choose $x$ to minimize $x+p(x) \underline{z}$, that is, he will choose $x(\underline{z})$.

It follows from the above that if $y<p(x(\underline{z})) \underline{z}$, a person will be unable to meet the requirement $\underline{z}$ by paying the insurance premium $\pi$ for coverage of $\underline{z}$; at $y=p(x(\underline{z})) \underline{z}$, a person can just meet the requirement by paying all his assets for the premium for coverage of $\underline{z}$; and above this asset level he will purchase less coverage than $\underline{z}$, but such that his available assets $y-\pi$ plus coverage equal $\underline{z}$; and at $y$ of $\underline{z}$ and above, coverage will not be purchased. Hence, social welfare may be written as

$$
\begin{aligned}
& \left.S(\underline{z})=\int_{p(x(\underline{z})) \underline{z}}^{\underline{z}} \quad\left\{\int_{x(\underline{z})+p(x(\underline{z})) \underline{z}}^{\infty}[g(x(\underline{z})) h)\right] f(g) d g\right\} w(y) d y
\end{aligned}
$$

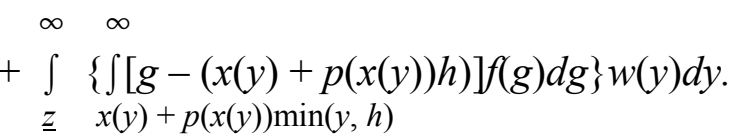

Now let us state

Proposition 3. Assume that liability insurers can observe an individual's level of care. Then the optimal liability insurance and asset requirement $\underline{z}^{*}$ is in $[0, h]$. In particular, a sufficient condition for $\underline{z}^{*}>0$ is that $\mathrm{E}(g)<p(0) h$.

Notes. That $\underline{z}^{*}$ will be positive if $\mathrm{E}(g)<p(0) h$ is explained essentially as before in Proposition 2: if this condition holds, then it is undesirable for individuals with no assets, who will not take any care, to engage in the activity, since their mean gain $\mathrm{E}(g)$ is less than the 
expected harm $p(0) h$ that they generate. The reason that $\underline{z}^{*}$ may be less than $h$ is that, if $\underline{z}^{*}=h$, then parties with assets too low to pay the premium for coverage of $h$ will be unable to engage in the activity, even though that may be undesirable ${ }^{22}$ this possibility is further discussed below in regard to the Remark of this section. That $\underline{z}^{*}$ cannot exceed $h$ follows because this could lead parties to take excessive care; if a person has to purchase insurance coverage above $h$ in order to comply, his incentive to take care will be socially excessive. Moreover, his expected expenses will be excessive so his decision whether to engage in the activity may be suboptimal. Hence, a requirement of $\underline{z}=h$ must be superior to a higher one.

Next, let us show that social welfare under $\underline{z}^{*}$ exceeds social welfare under the pure asset requirement $\underline{1}^{*}$. This is not surprising, for in the absence of liability insurance purchases, an individual with assets of $y<h$ will choose care of only $x(y)$ and bear costs of only $x(y)+$ $p(x(y)) y$. But when the individual is induced to purchase liability insurance by a requirement $\underline{z}$ exceeding his assets $y$, he will be led to choose higher care, of $x(\underline{z})$, which is desirable; and he also will bear higher costs, of $x(\underline{z})+p(x(\underline{z})) \underline{z}$, which may be desirable as well.

Proposition 4. Assume that liability insurers can observe an individual's level of care. Then social welfare under the optimal liability insurance and asset requirement $\underline{z}^{*}$ exceeds social welfare under the optimal pure asset requirement $\underline{y}^{*}$.

Notes. An outline of the proof is as follows. Consider $y^{*}$ and find the higher requirement, say $\underline{z}^{\prime}$, such that the insurance premium for coverage of $\underline{z}^{\prime}$ equals $\underline{y}^{*} \cdot{ }^{23}$ Hence,

\footnotetext{
${ }^{22}$ By contrast, in Shavell $(1986,2000)$ and Jost (1996), the optimal liability insurance requirement is full coverage $h$ when insurers can observe care. The reason for the difference in result is that in those articles the possibility that individuals are unable to pay the premium for full coverage is not taken into account.

${ }^{23}$ Such a $\underline{z}^{\prime}$ may not exist, but in that case an argument similar to that about to be sketched still applies, as shown in
} 
individuals with assets $y$ below $\underline{y}^{*}$ cannot engage in the activity; otherwise they can engage in the activity, but only by buying insurance if their assets are in $\left[\underline{y}^{*}, \underline{z}^{\prime}\right]$. It can be shown that social welfare is higher under $\underline{z}^{\prime}$ than under $\underline{y}^{*}$. In particular, individuals with $y<\underline{y}^{*}$ will be in the same situation under both regimes, namely, unable to engage in the activity. However, under $\underline{z^{\prime}}$ individuals with assets $y$ in $\left[\underline{y}^{*}, \underline{z}^{\prime}\right]$ who engage in the activity all take care of $x\left(\underline{z}^{\prime}\right)$ and bear expected expenses of $x\left(\underline{z}^{\prime}\right)+p\left(x\left(\underline{z}^{\prime}\right)\right) \underline{z}^{\prime}$, by claim (c) above; but under $\underline{y}^{*}$, such individuals take lesser care of only $x(y)$ and bear expected expenses of only $x(y)+p(x(y)) y$. Thus, under $y^{*}$, individuals with $y$ in $\left[y^{*}, \underline{z}^{\prime}\right]$ who engage in the activity behave less desirably, and they decide to engage in the activity more often when that is undesirable. Finally, individuals whose assets exceed $\underline{z}^{\prime}$ behave identically under the two regimes.

Next, let us compare social welfare under $\underline{z}=h$ to that under $\underline{y}^{*}$.

REMARK. Assume that liability insurers can observe an individual's level of care. Then social welfare under the full liability insurance and asset requirement $\underline{z}=h$ - liability insurance coverage plus assets must equal the harm - may or may not exceed social welfare under the optimal pure asset requirement $\underline{1}^{*}$.

Notes. If $\underline{z}=h$, then we know from claim (c) that all individuals who engage in the activity exercise care of $x(h)$ and bear expected costs of $x(h)+p(x(h)) h$. Hence, individuals who can pay the premium $p(x(h)) h$ will decide in a first-best way whether to engage in the activity and, if so, exercise first-best care. However, individuals with $y<p(x(h)) h$ are not able to pay the premium for coverage of $h$ and to engage in the activity, even though for some of these individuals $g>x(h)+p(x(h)) h$, and it would thus be socially desirable them to engage in the 
activity. ${ }^{24}$ Hence, if there are enough such individuals, $\underline{z}=h$ may be dominated by a low $\underline{y}^{*}$ that would allow many low asset individuals to engage in the activity who ought to do so. ${ }^{25}$

Otherwise, if enough individuals have assets above $p(x(h)) h$, then $\underline{z}=h$ will be superior to $\underline{y}^{*}$.

3.2 Insurers are not able to observe levels of care. Since insurers cannot observe care $x$ in this case, the premium $\pi$ for coverage $c$ cannot be a function of an individual's choice of $x$; however, it must be that $\pi=p(x) c$ for the $x$ that individuals choose. We assume that insurers can observe an individual's level of assets, so that $\pi$ can depend on $y{ }^{26}$

Because the premium does not depend directly on care, a situation of moral hazard exists, which bears comment because the character of the moral hazard may be different from the familiar one. The usual moral hazard is that insurance coverage dulls the incentive to take care because it directly lowers the amount that the person would otherwise pay in liability. For instance, if a person with assets of $\$ 200,000$ faces possible liability of $\$ 100,000$, he would pay $\$ 100,000$ without insurance coverage, whereas if he has coverage of, say, $\$ 80,000$, he only pays $\$ 20,000$ out of pocket, so his incentive to take care is reduced. This standard moral hazard would not apply, however, if the person would be bankrupted by liability in the absence of coverage as well as in its presence. For example, if the person with assets of $\$ 200,000$ faces possible liability of $\$ 1,000,000$, he will lose his entire wealth if held liable, just as he will lose

\footnotetext{
${ }^{24}$ That $g$ may exceed $x(h)+p(x(h)) h$ yet not be available to pay the insurance premium is possible if $g$ is nonmonetary or monetary but earned only by engaging in the activity.

${ }^{25}$ In this case, though, presumably the optimal $\underline{z}^{*}$ would be low, for we know from the previous proposition that welfare under the optimal requirement allowing insurance is higher than under $y^{*}$.

${ }^{26}$ Since $y$ is observable by the state (otherwise asset requirements could not be enforced), it is consistent to assume that $y$ is observable by insurers. It will be evident that this assumption is implicit in the analysis, since the choice of $x$ and thus $p(x)$ will depend on $y$.
} 
his entire wealth if his insurance coverage is, say, $\$ 500,000$. However, in this situation, the person's payment of the insurance premium - say it is $\$ 30,000$ - reduces the person's incentive to take care; for if he does not have coverage, he loses his entire $\$ 200,000$ if found liable, whereas if he does have coverage, his wealth after paying the premium will be only $\$ 170,000$, so he has less to lose if found liable and will therefore take less care. This premium-related moral hazard is, as noted earlier, essentially identical to the interest payment-related moral hazard emphasized by Pitchford (1995). One or the other of these moral hazards applies in the present context when individuals purchase insurance coverage.

Let us now discuss a number of claims about insurance and individuals' behavior assuming that $\underline{z} \leq h .^{27}$

(a) If an individual buys positive coverage $c$, he will take less care, resulting in lower social welfare, than if he did not buy coverage. To explain, consider the case in which an individual purchases positive coverage $c \leq h .^{28}$ His expected utility is

$$
y-\pi-x-p(x) \min (y-\pi, h-c),
$$

since if an accident occurs, he owes $h-c$ after using his coverage $c$ to pay liability, and his remaining assets are $y-\pi$. Note that $\operatorname{since} \min (y-\pi, h-c)<h$, care is less than the socially optimal level $x(h)$. By contrast, the person would choose $x$ to minimize $x+p(x) \min (y, h)$ if he did not have insurance coverage; and as $\min (y, h)>\min (y-\pi, h-c)$, he will take greater care if he does not have coverage. Since social costs are decreasing in $x$ when $x<x(h)$, social welfare is increasing in $x$; thus social welfare is lower on account of insurance coverage.

\footnotetext{
${ }^{27}$ Again, the case of $\underline{z}>h$ is discussed in the appendix.

${ }^{28}$ The case in which $c>h$ is discussed in the appendix.
} 
(b) If $y \geq \underline{z}$, so that individuals do not need to purchase insurance coverage to engage in the activity, individuals will not buy insurance coverage. The explanation for this claim is similar to that for the same one in the previous section, involving the point that, if assets $y$ are less than $h$, purchasing coverage is effectively spending on liability that one would not otherwise have to bear. Another reason why an individual would not want to buy coverage (applying even if $y$ exceeds $h$ ) is the moral hazard, that coverage leads to reduced care levels, which raises premium rates.

(c) If $y<\underline{z}$, so that individuals must purchase coverage in order to engage in the activity, individuals will buy the minimum necessary coverage - such that $y-\pi+c=\underline{z}$. Again, the explanation for this is similar to that for the same conclusion in the previous section, involving the point that purchasing coverage may be effectively spending on liability that one would not otherwise have to bear, and also now the additional point that the purchase of coverage leads to reduced care levels.

(d) If $y<\underline{z}$, individuals who engage in the activity purchase coverage and exercise less care than if they did not purchase coverage; they bear expected costs of $x+p(x) \underline{z}$. Because individuals must purchase coverage, we know from (a) that their care $x$ is lower than if they do not buy insurance coverage. From (c), we know that $y-\pi+c=\underline{z}$. Hence, if $\underline{z} \leq h$, they have no assets left if an accident occurs, so their expected utility is $y-\pi-p(x)(y-\pi)-x$; and since $\pi$ $=p(x) c$, for the chosen $x$, this reduces to $y-p(x) c-p(x)(\underline{z}-c)-x=y-p(x) \underline{z}-x$, so that expected costs are $x+p(x) \underline{z}$ as claimed.

These claims imply that social welfare has a similar form to (6), and it is readily shown that $\underline{z}^{*}$ is in $[0, h]$, but $\mathrm{E}(g)<p(0) h$ is not a sufficient condition for $\underline{z}^{*}>0$. The reason is that, 
when $\underline{z}$ is raised from 0 , although there is a social benefit from preventing individuals with $y=0$ from engaging in the activity, the level of care of individuals with positive $y<\underline{z}$ is reduced because of their purchase of insurance coverage, as noted in claim (a).

Now let us again compare social welfare under $\underline{z}^{*}$ to that under the optimal pure asset requirement. There is no necessary relationship. The reason is that liability insurance as a way of satisfying a requirement $\underline{z}$ has both a social disadvantage and an advantage relative to a pure asset requirement. The disadvantage is that an individual with assets $y$ who purchases insurance coverage exercises less care than $x(y)$, the care he would exercise if he did not purchase coverage. The advantage is that if individuals with $y<\underline{z}$ engage in the activity, they bear expected costs reflecting $\underline{z}$ (see claim (d)) rather than just $y$, which may improve their decision whether or not to engage in the activity. ${ }^{29}$ In particular, we have

Proposition 5. Assume that liability insurers cannot observe the level of care. Then social welfare under the optimal liability insurance and asset requirement $\underline{z}^{*}$ may or may not exceed social welfare under the optimal pure asset requirement $\underline{y}^{*}$.

Notes. First, to explain why $\underline{\underline{z}}^{*}$ may be superior to $\underline{\underline{ }}^{*}$, we consider a situation in which the exercise of care has little effect on the probability $p$, so that the dilution of care due to the purchase of insurance coverage is of small importance. Then the advantage of liability insurance in improving decisions whether or not to engage in the activity may lead to greater welfare under $\underline{z}^{*}$.

${ }^{29}$ Pitchford (1995) makes an an analogous comparison, between social welfare under optimal lender liability (lender liability in his model is similar to required liability insurance) and optimal asset requirements. He finds that optimal lender liability is equivalent to optimal asset requirements. The reason is essentially that in his model the only beneficial role of lender liability is to induce owners to invest more capital in firms, and this can be done directly by requiring that capital be invested. 
Consider a discrete example. ${ }^{30}$ Let $h=100$ and the probability of harm be $p=.1$ regardless of care; let $g=5$ with probability $2 / 3$ and $g=15$ with probability $1 / 3$. Since $p h=10$, it is first-best for all individuals with $g=15$ to engage in the activity and for none with $g=5$ to do so. Moreover, since those with $g=5$ are a majority, it is socially undesirable for all to engage in the activity rather than none to do so. Hence, $y^{*}=50$, for if $y$ is below 50 , the expected liability of individuals is less than 5 , so they all would engage in the activity. At $y^{*}$ and above, first-best behavior is obtained, for just individuals with $g=15$ engage in the activity. Now consider $\underline{z}=100$. Then in order to engage in the activity, individuals with $y<100$ will buy insurance, and their insurance costs plus expected liability will be 10 (see claim (d)). Consequently, all individuals with $y \geq 10$ are able to engage in the activity and for these levels of assets, only individuals with $g=15$ will decide to engage in the activity. Hence $\underline{z}=100$ is superior to $\underline{y}^{*}$-- because under this $\underline{z}$ but not $\underline{y}^{*}$, individuals with $g=15$ and assets between 10 and 50 engage in the activity, as is first-best. Thus $\underline{z}^{*}$, which may be different from $\underline{z}=100$, is superior to $\underline{y}^{*}$.

Second, to show that $\underline{y}^{*}$ may be superior to $\underline{z}^{*}$, we can construct a kind of converse situation, in which there is no social need to control the decision whether to engage in the activity of some individuals - because for them engaging in the activity is socially desirable yet use of required insurance coverage would dilute their incentives to take care. In this case, use of a pure asset requirement would be advantageous, since it does not dilute incentives to take care of those who engage in the activity, yet can still prevent those with assets below the requirement from engaging in the activity. 
In particular, consider the following example. Let $y=20$ or 50 , with equal probability and let $g=5$ or 13 with equal probability, so that for .25 of the population, $y=20$ and $g=5$, for another .25 of the population, $y=20$ and $g=13$, and so forth. Assume also that $h=100$ and that $x$ is 0 or 2.49 , where $p(0)=.15$ and $p(2.49)=.1$. Notice that $x=2.49$ is optimal if an individual engages in the activity, as spending 2.49 reduces expected harm from 15 to 10 . Consequently, the optimal probability of harm is .1, expected harm is 10 , and engaging in the activity leads to expected costs of 12.49 , so that the first-best outcome is for all individuals with $g=13$ to engage in the activity and take care but not for individuals with $g=5$ to engage in the activity.

Suppose that $y=50$. Then only individuals with $y=50$ can engage in the activity. Such individuals who engage in the activity choose $x=2.49$, for they will reduce their expected liability by $(.05)(50)=2.5$ by doing this. Hence, the expected expenses of such individuals will be 7.49. Thus, among individuals with $y=50$, those with $g$ of 13 will engage in the activity but not those with $g$ of 5 . In other words, behavior of individuals with $y=50$ is first-best. Social welfare will be $(.25)(13-12.49)=.13$.

It will be shown that social welfare is lower under any $\underline{z}$ than under $\underline{y}=50$. That will clearly imply that social welfare is lower under $\underline{z}^{*}$ than under $\underline{y}=50$ and thus than under $\mathrm{y}^{*} .{ }^{31}$ The nature of the demonstration is that, if $\underline{z}$ is not sufficiently high, then individuals with $y=20$ will be able to engage in the activity, will not take care, and lower social welfare. If, though, $\underline{z}$ is high enough to prevent those with $y=20$ from engaging in the activity, then those with $y=50$ will have diluted incentives to take care due to their required purchase of insurance coverage.

\footnotetext{
${ }^{30}$ See the appendix for a continuous version of the example that conforms to the assumptions of this article.

${ }^{31}$ In fact $y^{*}$ can be demonstrated to be any $y$ in the interval $(20,50]$.
} 
The details of this argument are given in the appendix.

Last, we have a

REMARK. Assume that liability insurers cannot observe the level of care. Then social welfare under the full liability insurance asset requirement $\underline{z}=h$ - liability insurance coverage plus assets must equal the harm - may or may not exceed social welfare under the optimal pure asset requirement $\underline{y}^{*}$.

Notes. That $\underline{z}=h$ may be superior to $\underline{y}^{*}$ was demonstrated in the example given in the previous proposition, where the dilution of care due to the purchase of insurance is not as important to social welfare as the beneficial effect of the insurance requirement on the decision about engaging in the activity. That $\underline{z}=h$ may be inferior to $\underline{y}^{*}$ is also implied by the previous proposition, since $\underline{z}^{*}$ may be inferior to $\underline{y}^{*}$. The possible inferiority of $\underline{z}=h$ to $\underline{y}^{*}$ may be seen directly as well. Consider a family of distributions of $g$ parameterized by $\lambda$ such that, as $\lambda \rightarrow \infty$, the probability that $g>p(0) h$ tends to 1 . Then, as $\lambda \rightarrow \infty$, the probability that it is socially desirable for an individual to engage in the activity tends to 1; also, for high $\lambda, \mathrm{E}(g)>p(0) h$, and thus $\underline{y}^{*}=0$. For high $\lambda$, let us compare $\underline{y}^{*}=0$ to $\underline{z}=h$. Consider an individual for whom $g>$ $p(0) h$. Under $y^{*}=0$, this individual will always engage in the activity, ${ }^{32}$ which is socially beneficial, and will take care of $x(y)$. Under $\underline{z}=h$, the outcome for any individual for whom $g>$ $p(0) h$ and $y<h$ will lower social welfare: either the individual will not be able to buy the insurance necessary to comply with $\underline{z}=h$ (this will be so for low $y$ ), or else he will be able to buy the insurance but will then take less care than $x(y)$. Since the probability that $g>p(0) h$ tends to 1 as $\lambda \rightarrow \infty$, it is thus clear that $\underline{y}^{*}$ is superior to $\underline{z}=h$ for $\lambda$ sufficiently high. 


\section{Concluding Comments}

In conclusion, let me note several issues of relevance to the analysis.

(a) Firms as injurers. It was assumed above that potential injurers are individuals, and I sketch here how the analysis would change were they firms. (An earlier version of this article considered firms as injurers. ${ }^{33}$ ) An important point in this regard is that when the parties harmed by firms are their own customers, financial responsibility requirements tend to be socially undesirable. The reason is that customers will factor the expected harm that they would suffer into their purchase decisions. Hence, their purchase decisions will be desirable, given their information about product risk; and firms will have a motive to reduce risk, since this may allow them to charge higher prices. ${ }^{34}$

When the parties harmed by firms are not their customers, the analysis of financial responsibility requirements would be similar to that here, but with a potential difference of significance. Recall that it was assumed above that the gain $g$ to an individual from engaging in the activity could not be used to pay liability insurance premiums; a justification was that the gain is nonmonetary (such as the utility from driving often is). Thus, a liability insurance requirement might undesirably prevent an individual with low assets from engaging in the activity even though his gain $g$ would exceed the expected harm (an individual might not be able to pay the liability insurance premium to drive despite large utility gains from doing so). If firms

\footnotetext{
${ }^{32}$ For his expected expenses are $\min _{x} x+p(x) \min (y, h) \leq \min _{x} x+p(x) h<p(0) h<g$.

${ }^{33}$ See Shavell (2002).

${ }^{34}$ The details of this argument, and whether the first-best outcome is obtained, depend on whether product risk is observable and on whether the assets of firms are observable or can be credibly revealed; see Shavell (2002).
} 
are able to borrow against their gains (which are monetary by their nature), then they cannot be undesirably discouraged from a business activity by having to pay liability insurance premiums. Hence, full compulsory liability insurance coverage will be desirable if insurers can observe care. But full liability insurance coverage still may be undesirable if insurers cannot observe care, due to moral hazard, and a pure asset requirement may again be superior to a liability insurance requirement.

(b) Endogeneity of assets. It was assumed in the analysis that the assets of parties are fixed, but in fact assets subject to liability are to some degree variable; individuals may earn or save, firms may raise capital, and both sometimes are able to shield assets from liability. The major effect of allowing for these factors on the conclusions would be to increase optimal minimal asset requirements, because the ability of parties to raise their level of assets diminishes the efficiency losses associated with asset requirements. ${ }^{35}$ Of course, optimal asset and liability insurance requirements would still tend to be less than harm because the cost of increasing assets would be positive (otherwise simply setting the requirement equal to harm would result in the first-best outcome, as all parties would costlessly be induced to comply and then would behave optimally).

(c) Alternative policies. There are a number of alternatives to asset and liability insurance requirements that may serve to ameliorate judgment-proof induced incentive problems. One is the use of vicarious liability: the extension of liability from the injurer to another party with whom the injurer has a relationship, for example, the extension of liability from a child to a

\footnotetext{
${ }^{35}$ As noted earlier, in Pitchford (1995) the (only) beneficial role of asset requirements is to induce owners to invest more capital in firms (and the optimal asset requirement is equal to the maximum amount that owners can invest).
} 
parent, from a small company working on a project to the general contractor, or from a corporation to a holding company or to a lender. Because under vicarious liability the joint assets of the two parties are at risk, vicarious liability tends to improve the injurer's decision about engaging in the activity. When the vicariously liable party is able to observe the level of care of the injurer, vicarious liability also tends to result in the exercise of better care, because the vicariously liable party will insist (or contract) on it; but when the vicariously liable party is not able to observe the level of care, the care decision will not be improved in a direct way, and possible disadvantages of vicarious liability may make partial vicarious liability desirable. ${ }^{36}$ (Not surprisingly, these conclusions resemble those concerning required liability insurance coverage, since the liability insurer is, by definition, liable for the harms caused by the insured.) Another policy alternative is, paradoxically, the opposite of requiring liability insurance: prohibiting the purchase of liability insurance. Risk averse injurers might well want to purchase some liability insurance coverage even though their assets are less than the potential harm they might cause. Hence, barring them from purchasing any liability insurance coverage might increase their level of care, due to their risk aversion. This policy is in fact sometimes employed, in that liability

\footnotetext{
${ }^{36}$ Sykes (1984) makes these general points and they are also contained in Shavell (1987). Pitchford (1995) focuses on vicarious liability on lenders when they cannot observe the level of care of firms and he analyzes two factors: vicarious liability may raise care, as it will make lenders want to reduce risk, which can be implicitly accomplished by owners putting up more capital, giving firms a greater reason to increase care; but vicarious liability may also lower care, as the price charged by lenders to cover their residual liability exposure reduces the assets of injurers; thus partial vicarious liability is generally optimal. Boyer and Laffont (1997) also examine vicarious liability on lenders and reach similar conclusions. Boyd and Ingberman (1997) emphasize that vicarious liability may lead vicariously liable parties to reduce their capital so as to avoid their exposure to liability, which may compromise the efficiency of their own production; hence partial vicarious liability may be desirable. Hiriart and Martimort (2003) present a general analysis of vicarious liability taking into account the relationship between firms that generate risks and buyers of their goods.
} 
insurance cannot be purchased against criminal fines and certain civil penalties. ${ }^{37}$ More general policies that can be used to combat the judgment-proof problem are criminal liability and direct safety regulation, and a promising avenue of research would be to determine on what grounds these various tools would hold an advantage over one another and/or can be fruitfully used in combination.

(d) Asset and liability insurance requirements as a means of assuring victims compensation. The explanation for the observed use of asset and liability insurance requirements may well lie mainly in society's desire to assure victims compensation through the legal system. However, the legal system appears to be an unusually costly way of delivering compensation to victims. ${ }^{38}$ Thus, asset and liability insurance requirements might find their best justification in the beneficial incentives that they generate.

\footnotetext{
${ }^{37}$ See Shavell $(1987,2000)$ for discussion of the barring of liability insurance.

${ }^{38}$ For example, a recent study, Tillinghast-Towers Perrin 2002, p. 12, reports that victims received only 42 per cent of payments made by defendant parties in a nationwide survey of the tort system (in other words, over half of all payments were absorbed by others, notably, by lawyers).
} 


\section{References}

Beard, T. Randolph. 1990. Bankruptcy and Care Choice. Rand Journal of Economics 21: 626634.

Boyd, James and Daniel E. Ingberman. 1997. The Search for Deep Pockets: Is "Extended Liability" Expensive Liability? Journal of Law, Economics, and Organization 13: 232258.

Boyer, Marcel, and Jean-Jacques Laffont. 1997. Environmental Risks and Bank Liability. European Economic Review 41: 1427-1459

Freixas, Xavier, and Jean-Charles Rochet. 1997. Microeconomics of Banking. MIT Press, Cambridge.

Hiriart, Yolande, and David Martimort. 2003. The Benefits of Extended Liability. mimeo. Department of Economics. University of Toulouse.

Jackson, Howell E., and Edward L. Symons, Jr. 1999. Regulation of Financial Institutions. West Group, St. Paul.

Jerry, Robert H. II. 1996. Understanding Insurance Law. $2^{\text {nd }}$ ed. Matthew Bender, New York. Jost, Peter-J. 1996. Limited Liability and the Requirement to Purchase Insurance. International Review of Law and Economics 16: 259-276.

Kahane, Y. 1977. Capital Adequacy and the Regulation of Financial Intermediaries. Journal of Banking and Finance 1: 207-18. 
Kim, Daesik, and Anthony M. Santoremo. 1988. Risk in Banking and Capital Regulation. Journal of Finance 43: 1219-33.

Pitchford, Rohan. 1995. How Liable Should a Lender Be? The Case of Judgement-Proof Firms and Environmental Risk. American Economic Review 85: 1171-1186.

Polborn, Mattias K. 1998. Mandatory Insurance and the Judgment-Proof Problem. International Review of Law and Economics 18: 141-146.

Rochet, Jean-Charles. 1992. Capital Requirements and the Behaviour of Commercial Banks. European Economic Review 36: 1137-78.

Shavell, Steven. 1986. The Judgment Proof Problem. International Review of Law and Economics 6: 45-58.

---- 1987. Economic Analysis of Accident Law. Harvard University Press, Cambridge.

----- 2000. On the Social Function and the Regulation of Liability Insurance. Geneva Papers on Risk and Insurance, Issues and Practice 25: 166-179.

----- 2002. Minimum Asset Requirements. Working Paper W9335, National Bureau of Economic Research.

Sykes, Alan. 1984. The Economics of Vicarious Liability. Yale Law Journal 91: 168-206.

Tillinghast - Towers Perrin. 2002. U.S. Tort Costs: 2000 Trends and Findings on the Costs of the U.S. Tort System. February 2002. Tillinghast-Towers Perrin. 


\section{APPENDIX}

Proof of Proposition 1. If $y<h$, then by (4) an individual will choose $x$ to minimize $x+p(x) y$, so that

(A1) $\quad 1>-p^{\prime}(x *) y$ implying that $x(y)<x^{*}$. Also, if $y<h$, we know from (4) that an individual will engage in the activity if and only if

(A2) $g \geq x(y)+p(x(y)) y$.

But since $y<h,(\mathrm{~A} 2)$ may hold even though $x(y)+p(x(y)) h>g$. Additionally, implicit differentiation of the first-order condition $1=-p^{\prime}(x) y$ with respect to $y$ gives $x^{\prime}(y)=$ $p^{\prime}(x) /\left(-p^{\prime \prime}(x) y\right)>0$. Finally, the derivative of social costs $x(y)+p(x(y)) h$ with respect to $y$ is $x^{\prime}(y)\left(1+p^{\prime}(x(y)) h\right)<0$, for $1=-p^{\prime}(x) y$ implies that $\left(1+p^{\prime}(x(y)) h\right)<0$.

Proof of Proposition 2. Differentiate (5) to obtain

$$
S^{\prime}(\underline{y})=\quad \begin{aligned}
& \infty \\
& \begin{array}{l}
\infty \\
x([y)+p(x(y)) \min (y, h)
\end{array}
\end{aligned}
$$

which can be rewritten as

$$
S^{\prime}(\underline{y})=\left\{\begin{array}{l}
x(\underline{y})+p(x(y)) h \\
\left\{\int([x(y)+p(x(y)) h]-g) f(g) d g-\int_{x(\underline{y})+p(x(\underline{y})) h}^{\infty}(g-[x(y)+p(x(y)) h]) f(g) d g\right\} w(y) . \\
x(\underline{y})+p(x(\underline{y})) \min (\underline{y}, h)
\end{array}\right.
$$

The first integral is the marginal social gain from preventing those individuals who should not engage in the activity from doing so, and the second integral is the marginal social loss from 
preventing those who should engage in the activity from doing so. At $y=0$, since $x(0)=0$, (A4) is

$$
S^{\prime}(0)=\underset{0}{\{(0) h}\left\{\begin{array}{c}
\{(0) h-g) f(g) d g \\
0
\end{array} \underset{p(0) h}{\infty}(g-p(0) h) f(g) d g\right\} w(0)=\{p(0) h-\mathrm{E}(g)\} w(0) .
$$

Hence, a sufficient condition for $y^{*}>0$ is $\mathrm{E}(g)<p(0) h$. To show that this condition is necessary for $\underline{y}^{*}>0$, observe that the term in braces in (A3) declines as $y$ rises in $[0, h)$, for the lower limit of integration rises with $y$ and $[x(y)+p(x(y)) h]$ falls with $y$. Hence, if $S^{\prime}(0) \leq 0$, then $S^{\prime}(y)<0$ for all $\underline{y}$ in $(0, \mathrm{~h})$. Therefore, if $\underline{y}^{*}>0$ holds, then $S^{\prime}(0)>0$, but this implies that $\mathrm{E}(g)<p(0) h$.

Also, note that, for any $y \geq h$, (A4) reduces to the second term, and since $x(y)=x^{*}$ for such $y$, we have

$$
S^{\prime}(\underline{y})=-\int_{x^{*}+p\left(x^{*}\right) h}^{\infty}\left(g-\left[x^{*}+p\left(x^{*}\right) h\right]\right) f(g) d g w(y)<0,
$$

so that $y^{*}$ must be less than $h$.

Proof of claim(a) of section 3.1. If the individual does not purchase coverage, his expected utility is

$$
y-x-p(x) \min (y, h) .
$$

If the individual purchases coverage and $c \leq h$, his expected utility is

$$
y-x-p(x) c-p(x) \min (y-p(x) c, h-c)
$$

because his premium is $p(x) c$ and, if liable, what he owes after coverage is paid to the victim is $h$ 
$-c$, and he pays this unless his remaining assets are lower. ${ }^{39}$

We want first to show that if $y<h$, then (A8) is less than (A7) for any $x$. In this case, (A7) is $y-x-p(x) y$. Now if $y-p(x) c \leq h-c$, then (A8) is $y-x-p(x) y-p(x) c(1-p(x))<y-x$ $-p(x) y$, so the individual is worse off buying coverage. If $y-p(x) c>h-c$, then (A8) is $y-x-$ $p(x) h<y-x-p(x) y$, so the individual is worse off buying coverage. Since (A8) is less than (A7) for any $x$ and the person can choose $x$, he must be better off not buying coverage.

Next let us show that if $y \geq h$, then (A7) equals (A8) for any $x$. In this case, (A7) is $y-x$ $-p(x) h$ and (A8) reduces to $y-x-p(x) h$ since $y-p(x) c<h-c$ cannot hold when $y \geq h$.

Consequently, the individual is just as well off not buying coverage as buying it, and we can assume for convenience that he does not buy coverage.

The remaining possibility is that the individual purchases coverage and $c>h$. Then his expected utility is

$$
y-x-p(x) c+p(x)(c-h)=y-x-p(x) h .
$$

Since this exceeds (A7) when $y<h$ and equals (A7) otherwise, we again conclude that the person is better off not buying coverage when $y<h$ and just as well off when $y \geq h$.

Proof of claim (b) of section 3.1. Assume first that $\underline{z} \leq h$. Then an individual's expected utility if he buys coverage $c$ such that $y-\pi+c=y-p(x) c+c \leq h$, is (A10) $(1-p(x))(y-p(x) c)-x$

\footnotetext{
${ }^{39}$ This expression can be derived from the more explicit expression for expected utility, namely, $(1-p(x))(y-p(x) c)$ $+p(x)(y-p(x) c+c-\min (y-p(x) c+c, h))-x=y-x-p(x) \min (y-p(x) c+c, h)$. Since $\min (y-p(x) c+c, h)=c+$ $\min (y-p(x) c, h-c)$, we obtain (A8). Similar derivations of expressions for expected utility below will not be given but can be verified by the reader.
} 
which is decreasing in $c$. If $c$ is high enough that $y-p(x) c+c>h$, then his expected utility is (A11) $(1-p(x))(y-p(x) c)-x+p(x)(y-p(x) c+c-h)=y-p(x) h-x$, which is independent of $c$. Hence, for any $x$, an individual is best off purchasing the minimum $c$ necessary to satisfy $\underline{z}$. Thus, in particular, when the individual chooses the optimal $x$, he must be best off when $c$ is the minimum necessary to satisfy $\underline{z}$.

Now assume that $\underline{z}>h$. Then, if an individual buys coverage sufficient to meet $\underline{z}$, he can pay $h$. Thus, his expected utility as a function of such $c$ is again given by (A11), so that he is indifferent about $c$; we can therefore assume that he buys the minimum necessary coverage.

Proof of claim (c) of section 3.1. If $\underline{z} \leq h$, the individual's expected utility is given by (A10), which may be rewritten as (A12) $y-p(x)(c+y-p(x) c)-x$

Now we know that $c+y-p(x) c=\underline{z}$, so that (A12) is $y-p(x) \underline{z}-x$, implying that the selected $x$ is $x(\underline{z})$, verifying the claim (c). We note also that, if $\underline{z}>h$, then the individual's expected utility is given by (A11), so he will choose $x(h)$, which is what he would choose if he did not have coverage and has assets of $\underline{z}$.

Proof of Proposition 3. The first term of (6) reduces to

$$
\left.[W(\underline{z})-W(p(x(\underline{z})) \underline{z})]\left\{\int_{x(\underline{z})+p(x(\underline{z})) \underline{z}}^{\infty}[g(x(\underline{z})) h)\right] f(g) d g\right\}
$$

where $W$ is the cdf of $w$. The derivative of this at $\underline{z}=0$ is readily verified to be 


$$
\left.\left.\left.w(0)(1-p(0)) \int_{0}[g-p(0)) h\right)\right] f(g) d g\right\}=-w(0)(1-p(0))[p(0) h-\mathrm{E}(g)] .
$$

The second term of (6) is identical to (5), with $\underline{z}$ playing the role of $\underline{y}$. Hence, the derivative of the second term of (6) at $\underline{z}=0$ is the derivative of (5) at $\underline{y}=0$, which was shown in (A5) to be $w(0)[p(0) h-\mathrm{E}(g)]$. Combining the right side of (A14) with this, we conclude that the derivative of (6) at $\underline{z}=0$ is $p(0) w(0)[p(0) h-\mathrm{E}(g)]$, which is positive if $\mathrm{E}(g)<p(0) h$. Hence, $\underline{z}^{*}>0$ if $\mathrm{E}(g)$ $<p(0) h$.

To show that $\underline{z}^{*} \leq h$ cannot be, it suffices to demonstrate that $\underline{z}>h$ is inferior to $\underline{z}=h$. If $\underline{z}=h$, it follows from claims (a) - (c) that behavior will be first-best for all individuals who have assets sufficient to pay the premium to engage in the activity. In particular, any individual who engages in the activity chooses first-best care $x(h)$ and bears expected expenses of $x(h)+$ $p(x(h)) h$. Thus, individuals will engage in the activity only if $g>x(h)+p(x(h)) h$, which is firstbest. To engage in the activity, however, it must be that assets $y \geq p(x(h)) h$; otherwise an individual will be unable to engage in the activity. Now if $\underline{z}>h$, it is immediately apparent that social welfare must fall, since fewer individuals are able to engage in the activity than under $\underline{z}=$ $h$ (and if they do engage in the activity, they cannot behave better than they do under $\underline{z}=h$, for their behavior is first-best when $\underline{z}=h$ ).

Proof of Proposition 4. Consider $\underline{y}^{*}$ and, if it exists, let $\underline{z}^{\prime}$ be the $\underline{z} \leq h$ such that the premium for coverage of $\underline{z}^{\prime}$ equals $\underline{y}^{*}$, that is, $p\left(x\left(\underline{z}^{\prime}\right)\right) \underline{z}^{\prime}=\underline{y}^{*}$. If such a $\underline{z}^{\prime}$ does not exist, note that $p(x(h)) h<\underline{y}^{*}($ since $p(x(0)) 0=0)$.

If $\underline{z}^{\prime}$ exists, then under $\underline{z}^{\prime}$ individuals with $y<\underline{y}^{*}$ cannot engage in the activity, for by 
claim (c), were they to engage in the activity, their premium would be $p\left(x\left(\underline{z}^{\prime}\right)\right) \underline{z}^{\prime}=\underline{y}^{*}$, but this exceeds $y$. Hence, individuals with $y<\underline{y}^{*}$ do not engage in the activity under either $\underline{z}^{\prime}$ or under $\underline{y}^{*}$. Now consider individuals with $y$ in $\left[\underline{y}^{*}, \underline{z}\right)$. Under $\underline{z}$, any such individual who engages in the activity will, by claim (c), choose $x\left(\underline{z}^{\prime}\right)$ and bear expenses of $x\left(\underline{z}^{\prime}\right)+p\left(x\left(\underline{z}^{\prime}\right)\right) \underline{z}^{\prime}$, whereas under $y^{*}$, any such individual will choose $x(y)$ and bear expenses of $x(y)+p(x(y)) y$. Since $x(y)+$ $p(x(y)) y<x\left(\underline{z}^{\prime}\right)+p\left(x\left(\underline{z}^{\prime}\right)\right) \underline{z}^{\prime}$, some individuals engage in the activity under $\underline{y}^{*}$ but not under $\underline{z}^{\prime}$, and some individuals engage in the activity under both $\underline{y}^{*}$ and $\underline{z}^{\prime}$ (but no individuals engage under $\underline{z}^{\prime}$ but not under $\underline{y}^{*}$ ). If an individual engages under $\underline{y}^{*}$ but not under $\underline{z}^{\prime}$, the individual must lower social welfare under $\underline{y}^{*}$, for $g<x\left(\underline{z}^{\prime}\right)+p\left(x\left(\underline{z}^{\prime}\right)\right) \underline{z}^{\prime}$ implies $g<x\left(\underline{z}^{\prime}\right)+p\left(x\left(\underline{z}^{\prime}\right)\right) h<x(y)$ $+p(x(y)) h$. If an individual engages under $\underline{y}^{*}$ and under $\underline{z}^{\prime}$, the individual must also lower social welfare under $\underline{y}^{*}$, for $x\left(\underline{z}^{\prime}\right)+p\left(x\left(\underline{z}^{\prime}\right)\right) h<x(y)+p(x(y)) h$. Last consider individuals with $y \geq \underline{z}^{\prime}$. We know from claim (a) that they do not buy coverage, so their behavior and social welfare in regard to them is the same under $\underline{z}^{\prime}$ and under $y^{*}$. We have thus shown that for some individuals, social welfare is the same under $\underline{z}^{\prime}$ as under $\underline{y}^{*}$, and for other individuals, social welfare is higher under $\underline{z}^{\prime}$ than under $\underline{y}^{*}$. Hence, social welfare is higher under $\underline{z}^{\prime}$ than under $\underline{y}^{*}$, and consequently higher under $\underline{z}^{*}$ than under $\underline{y}^{*}$.

If $\underline{z}^{\prime}$ does not exist, then consider $\underline{z}=h$ and let us show that this results in higher social welfare than $\underline{y}^{*}$. Since when $\underline{z}^{\prime}$ does not exist, $p(x(h)) h<\underline{y}^{*}$, we know that individuals in $\left[\underline{y}^{*}, h\right]$ can afford to pay the premium $x(h) h$ and can engage in the activity under $\underline{z}=h$, and that some individuals with $y<y^{*}$ can also afford to engage in the activity. Furthermore, by claim (c), any person who engages in the activity chooses $x(h)$ and bears expected expenses of $x(h)+p(x(h)) h$. Now consider individuals with $y<y^{*}$. Under $y^{*}$, such individuals do not engage in the activity. 
Under $\underline{z}$, some individuals will engage in the activity, and any such individual who does so will raise social welfare, for if he engages it must be that $g>x(h)+p(x(h)) h$. Next consider individuals with $y$ in $\left[y^{*}, h\right)$. By essentially the argument of the last paragraph applying to $\left[y^{*}\right.$, $\left.\underline{z}^{\prime}\right)$, it follows that if an individual engages in the activity under both $\underline{y}^{*}$ and $\underline{z}$, he will lower social welfare, and likewise if he engages in the activity only under $\underline{x}^{*}$. Individuals with $y \geq h$ behave in the same way under both $y^{*}$ and $\underline{z}=h$. Hence, again, social welfare must be higher under $\underline{z}$ than under $\underline{y}^{*}$, and thus higher under $\underline{z}^{*}$ than under $\underline{y}^{*}$.

Proof of Remark in section 3.1. To show that $\underline{z}=h$ may be superior to $\underline{y}^{*}$, we can construct an example as indicated in the Notes. We know that individuals for whom $y \geq p(x(h)) h$ will behave in a first-best way, whereas individuals for whom $y<h$ will not act in a first best way under $\underline{1}^{*}$. Consider $[p(x(h)) h, h-\epsilon]$ for some positive $\epsilon$ and a sequence of distributions of $y$ such that the probability $P$ that $\mathrm{y}$ is in the given interval is 1 in the limit. Then if the distribution of $y$ is such that $P$ is sufficiently close to $1, \underline{z}=h$ will be superior to $y^{*}$. For behavior under $\underline{z}=h$ is first-best in this interval, so social welfare approaches first-best as $P$ approaches 1 . Yet since $y$ in the interval are at least $\epsilon$ below $h$, social welfare under $y^{*}$ must be bounded below first-best.

To show that $\underline{z}=h$ may be inferior to $\underline{x}^{*}$, we can again construct an example as suggested by the Notes. Consider the interval $[0, p(x(h) h-\epsilon]$ for some positive $\epsilon$ and a sequence of distributions of $y$ such that the probability $P$ that $y$ is in the given interval is 1 in the limit. Also, consider the interval $[h+\delta, \infty)$ for some positive $\delta$ and a sequence of distributions of $g$ such that the probability $Q$ that $g$ is in the given interval is 1 in the limit. Then for distributions such that 
$P$ and $Q$ are sufficiently close to $1, \underline{y}^{*}$ will be superior to $\underline{z}=h$. In particular, when $g$ is in the interval, it is clearly desirable for individuals to participate in the activity, and they can do so under $y=0$, so that as $Q$ tends to 1 with $\underline{y}=0$, social welfare must be positive and bounded above zero. However, as $P$ tends to 1 , social welfare tends to 0 since the probability that an individual is able to engage in the activity tends to 0 . Thus, for $P$ and $Q$ sufficiently high, it must be that $\underline{y}=0$, and thus $\underline{y}^{*}$, is superior to $\underline{z}=h$.

Proof of claim (a) of section 3.2. It remains to consider the case in which $c>h$. In that case, an individual's expected utility is $y-\pi-x+p(x)(c-h)$, so he chooses $x=0$, whereas he would select a positive $x$ less than or equal to $x(h)$ if he did not have coverage, so that social welfare would be higher.

Proof of claim (b) of section 3.2. If the individual does not purchase coverage, his expected utility is (A7).

If he does purchase positive coverage and $c \leq h$, his expected utility is (A15) $y-\pi-x-p(x) \min (y-\pi, h-c)=y-p(x) c-x-p(x) \min (y-p(x) c, h-c)$.

This is because $\pi$ must equal $p(x) c$ for the $x$ that the individual selects, since premium are actuarially fair.

We want first to show that if $y<h$, then the individual is better off not purchasing coverage. The argument given in the proof of claim (a) of section 3.1 applies to show this.

Next let us show that if $y \geq h$, then the individual is better off not purchasing coverage. In this case, (A7) is $y-x-p(x) h$, and since the person chooses $x$ to minimize this, his expected 
utility is $y-x(h)-p(x(h)) h$. Also, since $y-\pi>h-c$ in this case, the left side of (A15) reduces to $y-\pi-x-p(x)(h-c)$. Hence, the person chooses $x(h-c)$. And since $\pi=p(x) c$ for the chosen $x$, (A15) reduces to $y-x-p(x) h$, or to $y-x(h-c)-p(x(h-c)) h<y-x(h)-p(x(h)) h$, for $x(h)$ minimizes $x+p(x) h$. Hence, the individual is worse off buying coverage. (In effect, the moral hazard due to purchase of insurance leads him to take less care than is optimal.)

The remaining possibility is that the individual purchases insurance and $c>h$. In this case if he buys coverage, his expected utility is

$$
y-x-\pi+p(x)(c-h)=y-x-p(x) c+p(x)(c-h)=y-x-p(x) h
$$

since $\pi=p(x) c$ for his chosen $x$. From the left side, it is clear that $x=0$. Hence, his expected utility is $y-p(0) h$, which exceeds $y-x(h)-p(x(h)) h$, which is greater than or equal to the minimized value of (A7). Hence the person is better off not buying coverage.

Proof of claim (c) of section 3.2. Assume first that $\underline{z}<h$. Consider the situation if an individual buys insurance coverage $c$ such that he can meet $\underline{z}$ but not enough to leave him with positive assets after paying what he is able to in liability; that is, $c$ is such that $\underline{z} \leq y-\pi+c \leq h$. Then his expected utility is (A17) $\mathrm{E}(c)=\max _{x}(1-p(x))(y-\pi(c))-x$ where $\pi(c)=p(x) c$ for the selected $x$, which will be denoted in this proof by $x_{I}(c)$. We claim that $\mathrm{E}(c)$ is decreasing in $c$. To show this, it suffices to show that $\pi(c)$ is strictly increasing in $c$, for $\max _{x}(1-p(x))(y-\pi)-x$ is clearly strictly decreasing in $\pi$. Now consider $c_{1}<c_{2}$ and suppose that coverage $c_{1}$ were offered at the premium $\pi\left(c_{2}\right)$. Then the individual would exercise care of $x_{I}\left(c_{2}\right)$ (since care is determined exclusively by $\pi$-- see (A17) -- not by $c$ itself), so that $p$ would 
equal $p\left(x_{I}\left(c_{2}\right)\right) c_{1}$. But this means that the insurer would make profits; since $p\left(x_{I}\left(c_{2}\right)\right) c_{2}=\pi\left(c_{2}\right)$, we have $p\left(x_{I}\left(c_{2}\right)\right) c_{1}<\pi\left(c_{2}\right)$. This in turn means that the premium such that profits are zero for $c_{1}$ must be lower than $\pi\left(c_{2}\right)$, that is $\pi\left(c_{1}\right)<\pi\left(c_{2}\right)$. Since, then $\mathrm{E}(c)$ is decreasing in $c, c$ must be the minimum such $c$ allowing him to meet $\underline{z}$.

Let us now consider the situation where $c$ is such that $y-\pi+c \geq h$. Then expected utility is

$$
\begin{aligned}
\mathrm{E}(c) & =\max _{x}(1-p(x))(y-\pi(c))+p(x)(y-\pi(c)+c-h)-x \\
& =\max _{x} y-\pi(c)-p(x)(h-c)-x
\end{aligned}
$$

Thus, it is clear that $x_{I}(c)$ is decreasing in $c$ for the $c$ under consideration. Additionally, since $\pi(c)=p\left(x_{I}(c)\right) c, \mathrm{E}(c)$ reduces to $y-p\left(x_{I}(c)\right) h-x_{I}(c)$. Since $x_{I}(c)$ is decreasing in $c$, it follows that $\mathrm{E}(c)$ is decreasing in $c$. Thus, $\mathrm{E}(c)$ is highest when $c$ is lowest, such that $y-\pi+c=h$, but it was shown above that this $c$ is worse for the individual than $c$ such that $y-\pi+c=\underline{z}$.

Now assume that $\underline{z} \geq h$. Thus, the individual's expected utility as a function of such $c$ is again given by (A18), and essentially the argument just given shows that $c$ will be chosen such that $y-\pi+c=\underline{z}$.

Proof of claim (d) of section 4.2. This is clear from the text. However, in the case where $\underline{z}>h$, the claim is that expected expenses are $x+p(x) h$. This follows because, if $\underline{z}>h$, a person has assets left if an accident occurs, so his expected utility is $(1-p(x))(y-\pi)+p(x)(y-\pi+c-$ h) $-x=y-\pi-p(x)(h-c)-x=y-p(x) c-p(x)(h-c)-x=y-p(x) h-x$, so his expected costs are $x+p(x) h$. 
Proof of Proposition 5. Two examples establish the proposition.

Example in which welfare is higher under $\underline{z}^{*}$ than under $\underline{y}^{*}$. In the text, an example was given in which welfare under $\underline{z}=100$ exceeded that under $\underline{x}^{*}=50$, and which differed from the assumptions of the model in two respects: $g$ was not continuously distributed but was discrete, with mass points at 5 and 15 ; and $p(x)$ was not decreasing in $x$ but fixed at .1. If the discrete distribution of $g$ is replaced with a continuous distribution with mass of nearly $2 / 3$ sufficiently concentrated about 5 and mass of nearly $1 / 3$ sufficiently concentrated about 15 , it is clear that $\underline{z}=$ 100 will remain superior to $y^{*}$, which will be close to 50 . Now consider functions of the form $p(x ; \lambda)=.1+\lambda p(x)$ for positive $\lambda<.9$ for any $p(x)$ of the type assumed in the model; it is evident that for any such $\lambda, p(x ; \lambda)$ is of the type assumed in the model. Now as $\lambda \rightarrow 0$, it must be that $x(\lambda) \rightarrow 0$, where $x(\lambda)$ denotes the optimal choice of $x$ given $\lambda ;^{40}$ and it is obvious that as $\lambda \rightarrow 0$, $p(x(\lambda)) \rightarrow .1$. Hence, it is clear that if we choose $\lambda$ sufficiently small and replace $p(x) \equiv .1$ with $p(x ; \lambda)$, then $\underline{z}=100$ will still be superior to $\underline{y}^{*}$, which will be close to 50 .

Example in which social welfare is higher under $\underline{y}^{*}$ than under $\underline{z}^{*}$. We complete here the discrete example described in the Notes to the Proposition, from which it would be straightforward to construct a continuous example along the lines described above for the other example.

If $\underline{z} \leq 20$, individuals will not need to buy liability insurance and will not do so, by claim (b) of section 3.2. Then all individuals with $y=20$ will engage in the activity and will choose $x$ $=0$; for spending 2.49 lowers their expected liability by only $(.05)(20)=1$, and their expected

\footnotetext{
${ }^{40}$ We want to show that for any positive $\delta, \mathrm{x}(\lambda)<\delta$ for $\lambda$ sufficiently low. Consider $\lambda<\delta / h$. Then $x \geq \delta$ is inferior to $x=0$, since the reduction in expected liability from a positive $\mathrm{x}$ is bounded by $\lambda h$ but the $x$ in question is at least $\delta$,
} 
expenses are thus $(.15)(20)=3<5$. Individuals with $y=50$ will also engage in the activity and behave in a first-best way as just described above. Because individuals with $y=20$ engage in the activity and do not take care, social welfare will be lower than under $y=50$ (social welfare will fall by $(.25)(15-5)+(.25)(15-13))$. Next, consider $\underline{z}$ in the interval $(20,50]$. It is clear that individuals with $y=50$ will again behave in a first-best way. We will show that the behavior of individuals with $y=20$ will again lower social welfare, and thus that the outcome will be inferior to that under $y=50$. For an individual with $y=20$ to engage in the activity, he must purchase liability insurance. Also, note that if an individual with $y=20$ engages in the activity, he will choose $x=0$, for since he pays a positive insurance premium, his available assets will be less than even 20; thus the probability of harm will be .15 . To determine whether individuals with $y$ $=20$ will engage in the activity, recall from claim (d), that if they engage in the activity, their expected expenses will be $x+p(x) \underline{z}$, implying that they will be $.15 \underline{z}$. Thus, even if $\underline{z}=50$, expected expenses are 7.5, so that at least individuals with $g=13$ will engage in the activity, but that will lower social welfare, as expected harm is 15 . (If individuals with $g=5$ engage in the activity, social welfare will be even lower.) Last, consider $\underline{z}>50$. Such a $\underline{z}$ will lead to a decline in social welfare among individuals with $y=20$ unless $\underline{z}$ is high enough to discourage them from engaging in the activity. For this to be true, $.15 \underline{z}$ must exceed 13 , meaning that $\underline{z}$ must exceed 86.66. However, when $\underline{z}$ is at least 86.66 , those individuals with $y=50$ must buy liability insurance exceeding 36.66 to meet $\underline{z}$, and the premium payment they make will in turn eliminate their incentive to take care. ${ }^{41}$ Hence, social welfare also falls when $\underline{z}$ exceeds 86.66 .

and $\delta>\lambda h$. It follows that $x(\lambda)<\delta$.

${ }^{41}$ To meet the requirement, coverage c must satisfy $50-\pi+c=86.66$, so $c=36.66+\pi$. Now if individuals do 
Proof of Remark in section 3.2. This is clear from the Notes to the Proposition in the

text.

have an incentive to take care, then $p=.1$, so $\pi$ for coverage of 36.66 would be 3.66 . This means that their remaining assets $50-\pi$ are less than 46.34. But taking care would then benefit an individual by less than $(.05)(46.34)=2.32<2.49$. This contradicts the assumption that they would take care. 